\title{
Asian options with zero cost-of-carry: EEX options on freight and iron ore futures
}

\author{
Espen Gaarder Haug ${ }^{1}$
}

Received: 7 February 2020 / Accepted: 27 April 2020 / Published online: 26 May 2020

(c) The Author(s) 2020

\begin{abstract}
The Turnbull-Wakeman (J Financ Quant Anal 26:377, 2003) formula is a well-known formula for continuous arithmetic average rate options. However, the TurnbullWakeman formula was originally only developed for Asian options when the cost-of-carry is different from zero. In many commodity and energy markets where Asian options frequently trade, the average is typically based on futures or forward prices, that is to say, the cost-of-carry for the underlying asset is zero. Options on stocks can also have a cost-of-carry of zero. If the continuous dividend yield is equal to the risk-free rate, then the extension given in this note can be used in that case as well.
\end{abstract}

Keywords Asian options - Arithmetic average rate options - Zero cost-of-carry · European energy exchange $\cdot$ Freight futures options $\cdot$ Iron ore futures options

JEL Classification $\mathrm{G} 1 \cdot \mathrm{G} 13$

\section{Introduction}

Arithmetic average rate options are popular in several commodity markets and also in freight contracts. Most Asian options that trade on exchanges are options on the arithmetic average of the futures price and not on the spot price. Turnbull and Wakeman originally developed their formula for Asian options on the spot price, that is, for an underlying with a cost-of-carry different than zero. Yet, it costs nothing to carry a futures contract. One has to put up margin for futures, but one typically receives an interest rate on the margin money, and several exchanges even allow one to put Treasury bills up as margin collateral. Thus, at least in theory, the cost-of-carry for a futures contract is zero.

\footnotetext{
$凶 \quad$ Espen Gaarder Haug

espenhaug@mac.com

1 The Business School, Norwegian University of Life Sciences, Ås, Norway
} 
The Turnbull-Wakeman formula can be extended to hold for options on futures (with zero cost-of-carry); we first showed this work in an unpublished working paper in 2006. In 2017, the European Energy Exchange announced that they had switched from using the Black-76 formula (Black 1976) for settling freight futures options to the Turnbull-Wakeman formula as modified by Haug in 2006 (see The European Energy Exchange 2017). From 2018 on, the European Energy Exchange has been settling both freight futures options and iron ore options based on our modified Turnbull-Wakeman formula. In their own words, "The calculation of prices for options on freight and iron ore futures is based on the mathematical equation of the Turnbull and Wakeman formula extended by Espen Gaarder Haug" The European Energy Exchange (2018).

\section{Cost-of-carry zero solution}

In the case of Asian options when the cost-of-carry is zero, the Turnbull-Wakeman formula does not hold but must be modified. Turnbull and Wakeman assumed the spot price was log-normally distributed and followed a geometric Brownian motion. In the same way, we initially assume the future price is log-normally distributed and has normally distributed returns. That is, we assume that the future price will then follow a geometric Brownian motion process

$$
d F_{t}=\sigma F_{t} d Z
$$

where $d Z$ is a standard Wiener process. If the future price is log-normally distributed, then the arithmetic average of the future price will not be log-normally distributed. Still, the approximate log-normality of sums of log-normals is a well-known rule of thumb, also known as the Fenton-Wilkinson approximation (Fenton 1960; Dufresne 2004). The same methodology was described in the field of optics in a paper by Mitchell in 1968 (Mitchell 2018), which Turnbull and Wakeman refer to as well. More precisely, we find the log-normal approximation for a sum of log-normals by matching the first two moments of the exact distribution, and then, we assume the distribution of the arithmetic average is approximately log-normally distributed. This is similar to the approach Turnbull and Wakeman used, with one major exception, namely that the underlying asset of the arithmetic average is the future price and not the spot price. Most exchange-traded average options are likely linked to the arithmetic of the future price and not of the spot price.

If we assume the arithmetic average is approximately log-normally distributed, then in order to value an Asian futures option, we will simply need to adjust the volatility of the Black-76 formula. This entails replacing the futures volatility $\sigma$ with the volatility of the average on the futures $\sigma_{A}$ :

$$
\begin{aligned}
& c_{A} \approx e^{-r T}\left[F N\left(d_{1}\right)-X N\left(d_{2}\right)\right], \\
& p_{A} \approx e^{-r T}\left[X N\left(-d_{2}\right)-F N\left(-d_{1}\right)\right],
\end{aligned}
$$

where $T$ is the time to maturity, $r$ is the risk-free rate, $F$ is the futures price, and $X$ is the strike price. 


$$
d_{1}=\frac{\ln (F / X)+T \sigma_{A}^{2} / 2}{\sigma_{A} \sqrt{T}}, \quad d_{2}=d_{1}-\sigma_{A} \sqrt{T},
$$

where

$$
\sigma_{A}=\sqrt{\frac{\ln (M)}{T}}, \quad M=\frac{2 e^{\sigma^{2} T}-2 e^{\sigma^{2} \tau}\left[1+\sigma^{2}(T-\tau)\right]}{\sigma^{4}(T-\tau)^{2}},
$$

where $\tau$ is the time to the beginning of the average period and $\sigma$ is the volatility of the futures contract, and $M$ is the second moment of the exact distribution. If the option is into the average period, the strike price must be replaced by $Y$ and the option value must be multiplied by $\frac{T}{T_{2}}$, where

$$
Y=X \frac{T_{2}}{T}-F_{A} \frac{\left(T_{2}-T\right)}{T},
$$

where $T_{2}$ is the original time in the average period and $F_{A}$ is the average futures price during the realized or observed time period $T_{2}-T$.

If $Y$ should be negative, the call option will very likely be exercised at maturity and the value will become the discounted value of the expected average at maturity $E_{Q}[A]$ minus the strike price: $E_{Q}[A]-X$. The expected average is equal to

$$
E_{Q}[A]=\frac{F_{A}\left(T_{2}-T\right)}{T}+F \frac{T}{T_{2}} .
$$

For a put, the value will be 0 if $Y$ is negative. This is basically the Turnbull-Wakeman formula extended to Asian options on futures.

It is helpful to understand the historical background of the formula. Turnbull and Wakeman published their formula in 1991, the same year I started my first job trading and market making in options. I was not involved in Asian options, but I was trading standard fixed income options for Den norske Bank as a junior market maker and trader. In 1999, I moved to the USA and set up electricity option trading operations for a multibillion-dollar hedge fund. In May 1999, I derived a new version of the Turnbull-Wakeman formula that also held for options on futures - that modification is now used daily by the EEX for settlement. It is a straightforward derivation based on one assumption - that the underlying asset is valued as the arithmetic average of a future contract rather than a spot contract. It is worth noting that the most welldeveloped energy option market in the late 1990s was in Europe and some of the options traded then were done Asian style, or, more precisely, on the arithmetic average of futures contracts. The Turnbull-Wakeman formula was a well-known closed-form approximation for arithmetic Asian options. However, I saw that it could not hold for arithmetic average options on futures, based on the equations and on the numerical inputs and outputs from the formula.

By following standard derivations, I re-derived the formula to hold when the costof-carry for the underlying asset, that is for futures and forwards, was zero. I actually held the modified version secret while I was involved in average rate option trading, 
but ultimately I decided for the common good to put out a working paper and made it available on my webpage. This working paper became quite popular among option trading professionals and quants then and continues to generate interest today. One might argue that it is not an ideal formula, as it assumes a continuous time average and, in practice, options are calculated on a discrete time average. Such details could be important for market makers and traders. More advanced models also exist, such as the Haug et al. (2003) discrete term average price formula that takes the term structure of volatility and the discrete sampling of the average into account; this reflects the actual case in practice. However, for quick settlement valuation, the modified TurnbullWakeman formula has clearly shown its benefits, as it is easily to handle and is used in practice by exchanges such as EEX. As an additional practical note, for option traders, it is typically more important to know how to use sophisticated heuristics properly than to debate over precisely what formula one will use or how it has been derived, as discussed by Haug and Taleb (2011). For example, it is widely known that the underlying asset for stocks and commodities in general typically is not lognormally distributed and the returns therefore are not normally distributed, but in general have fatter tails and higher peaks than the Gaussian distribution, something that has been known empirically for a long time, see (Mitchell 1915; Mills 1927; Taleb 2007). Whether or not it should converge to Gaussian for a very large number of observations is not obvious and Mandelbrot as well as Taleb, for example, have shown that the convergence in many cases can be extremely slow at best. In practice, it is therefore more about how the option formula is used and how options are hedged, than how the formula has been derived. This could also explain why simple formulas often are preferred among many traders, compared to more complex models. In a simpler model, the assumptions are clear, and one can more easily know about the weaknesses and strengths in the model.

\section{Conclusion}

The original Turnbull and Wakeman (1991) formula was used for continuous time arithmetic Asian options on the spot price. Most exchange-traded Asian options are related to the average of the futures price. The adjusted formula presented in this paper is based on a working paper originally put out in 2006, and today it is the standard formula used by the European Energy Exchange in settlement calculations for their freight and iron ore futures options. Further research could entail extensions related to the term structure of volatility and taking the discrete sampling of the average into account.

Acknowledgements Open Access funding provided by Norwegian University of Life Sciences.

\section{Compliance with ethical standards}

\section{Conflict of interest none.}

Open Access This article is licensed under a Creative Commons Attribution 4.0 International License, which permits use, sharing, adaptation, distribution and reproduction in any medium or format, as long as you give 
appropriate credit to the original author(s) and the source, provide a link to the Creative Commons licence, and indicate if changes were made. The images or other third party material in this article are included in the article's Creative Commons licence, unless indicated otherwise in a credit line to the material. If material is not included in the article's Creative Commons licence and your intended use is not permitted by statutory regulation or exceeds the permitted use, you will need to obtain permission directly from the copyright holder. To view a copy of this licence, visit http://creativecommons.org/licenses/by/4.0/.

\section{References}

Black, F.: The pricing of commodity contracts. J. Financ. Econ. 3, 167 (1976)

Dufresne, C.: The log-normal approximation in financial and other computations. Adv. Appl. Probab. 36, 747 (2004)

Fenton, L.F.: The sum of log-normal probability distributions in scattered transmission systems. IRE Trans. Commun. Syst. 8, 57 (1960)

Haug, E.G., Haug, J., Margrabe, W.: Asian pyramid power, Wilmott Magazine, March (2003)

Haug, E.G., Taleb, N.N.: Option traders use (very) sophisticated heuristics, never the Black-Scholes-Merton formula. J. Econ. Behav. Org 77, 97 (2011)

Mills, F.C.: The Behaviour of Prices. The Messenger Press, New York (1927)

Mitchell, W.C.: An introduction to index numbers and wholesale prices in the United States and foreign countries, Bulletin No. 173 of the U.S. Bureau of Labor Statistics, The Messenger Press, New York (1915)

Mitchell, R.L.: Permanence of the log-normal distribution. J. Opt. Soc. Am. 58, 1267 (2018)

Taleb, N.N.: The Black Swan. Random House, New York (2007)

The European Energy Exchange: customer information 2017-05-24, Leipzig, (2017)

The European Energy Exchange: settlement pricing procedure, English Version 5.04, Leipzig, (2018)

Turnbull, S.M., Wakeman, L.M.: A quick algorithm for pricing European average options. J. Financ. Quant. Anal. 26, 377 (1991)

Publisher's Note Springer Nature remains neutral with regard to jurisdictional claims in published maps and institutional affiliations. 